\title{
Engineering a Decoy Substrate in Soybean to Enable Recognition of the Soybean Mosaic Virus Nla Protease
}

\author{
Matthew Helm, ${ }^{1}$ Mingsheng Qi, ${ }^{2}$ Shayan Sarkar, ${ }^{2}$ Haiyue $\mathrm{Yu}^{2}{ }^{2}$ Steven A. Whitham, ${ }^{2}$ and Roger W. Innes ${ }^{1, \dagger}$ \\ ${ }^{1}$ Department of Biology, Indiana University, Bloomington, IN 47405, U.S.A. \\ ${ }^{2}$ Department of Plant Pathology and Microbiology, lowa State University, Ames, IA 50011, U.S.A.
}

Accepted 22 January 2019.

\begin{abstract}
In Arabidopsis, recognition of the AvrPphB effector protease from Pseudomonas syringae is mediated by the disease resistance (R) protein RPS5, which is activated by AvrPphB-induced cleavage of the Arabidopsis protein kinase PBS1. The recognition specificity of RPS5 can be altered by substituting the AvrPphB cleavage site within PBS1 with cleavage sequences for other proteases, including proteases from viruses. AvrPphB also activates defense responses in soybean (Glycine max), suggesting that soybean may contain an $R$ protein analogous to RPS5. It was unknown, however, whether this response is mediated by cleavage of a soybean PBS1-like protein. Here, we show that soybean contains three PBS1 orthologs and that their products are cleaved by AvrPphB. Further, transient expression of soybean PBS1 derivatives containing a five-alanine insertion at their AvrPphB cleavage sites activated cell death in soybean protoplasts, demonstrating that soybean likely contains an AvrPphB-specific resistance protein that is activated by a conformational change in soybean PBS1 proteins. Significantly, we show that a soybean PBS1 decoy protein modified to contain a cleavage site for the soybean mosaic virus (SMV) NIa protease triggers cell death in soybean protoplasts when cleaved by this protease, indicating that the PBS1 decoy approach will work in soybean, using endogenous $P B S 1$ genes. Lastly, we show that activation of the AvrPphB-dependent cell death response effectively inhibits systemic spread of SMV in soybean. These data also indicate that decoy engineering may be feasible in other crop plant species that recognize AvrPphB protease activity.
\end{abstract}

'Decoy' engineering is an emerging approach that aims to expand the recognition specificity of intracellular disease

This research was funded, in part, by BASF Plant Sciences and we have filed for a patent on the use of soybean PBS1 genes to engineer recognition of diverse pathogen proteases. BASF has first rights of refusal to license this patent

${ }^{\dagger}$ Corresponding author: R. W. Innes; rinnes@indiana.edu

Funding: This work was supported by the National Science Foundation Integrative Organismal Systems grant awarded to RWI and SAW (grant number IOS-1551452) and by funding from BASF Plant Science. M. Helm was supported by a predoctoral fellowship from the United States Department of Agriculture National Institute of Food and Agriculture (201867011-28023).

*The $\boldsymbol{e}$-Xtra logo stands for "electronic extra" and indicates that six supplementary figures and one supplementary table are published online.

(C) 2019 The American Phytopathological Society resistance proteins in order to generate entirely novel recognition specificities. In this approach, a host protein is engineered to function as a substrate for pathogen-derived effectors (i.e., a decoy) (Giannakopoulou et al. 2015; Harris et al. 2013; Maqbool et al. 2015; Segretin et al. 2014; Stirnweis et al. 2014). Effector-dependent modification of the decoy triggers activation of an intracellular disease resistance protein, culminating in a hypersensitive response (HR) and disease resistance (Giannakopoulou et al. 2015; Harris et al. 2013; Maqbool et al. 2015; Segretin et al. 2014; Stirnweis et al. 2014). An example of using decoys to expand the recognition spectrum of an intracellular disease resistance protein is the Arabidopsis RPS5PBS1 recognition module (Kim et al. 2016). In this system, Arabidopsis PBS1 functions as a substrate for the Pseudomonas syringae pv. phaseolicola cysteine protease AvrPphB (Zhu et al. 2004). Cleavage of Arabidopsis PBS1 by AvrPphB activates the Arabidopsis nucleotide-binding leucine-rich repeat (NLR) protein RPS5, which confers resistance to $P$. syringae (Ade et al. 2007; DeYoung et al. 2012; Shao et al. 2003). Kim et al. (2016) demonstrated that the AvrPphB cleavage site sequence within Arabidopsis PBS1 can be substituted with a protease cleavage site sequence recognized by other pathogenderived proteases, thereby generating a synthetic PBS1 decoy. Protease-dependent cleavage of the PBS1 decoy enables activation of RPS5, which was demonstrated for proteases derived from both bacteria and viruses (Kim et al. 2016). These findings thus provide compelling evidence that engineering decoys based on the Arabidopsis RPS5-PBS1 recognition module may be an effective NLR gene-based strategy to control plant diseases in crop plants.

Creation of a decoy recognition system in crop plants based on PBS1 may not require use of Arabidopsis genes. Arabidopsis PBS1 is a well-conserved defense gene, with orthologs present in monocot and dicot crop plant species (Caldwell and Michelmore 2009). Importantly, AvrPphB has been shown to cleave PBS1 orthologs from both wheat and barley and to induce an HR in these species as well as in soybean (Carter et al. 2019; Russell et al. 2015; Sun et al. 2017). Carter et al. (2019) recently mapped the $\mathrm{AvrPphB}$ response in barley to a single locus containing an NLR gene, AvrPphB Response 1 (Pbrl). Significantly, PBR1 coimmunoprecipitates with barley and Nicotiana benthamiana PBS1 proteins and coexpression of PBR1 with AvrPphB activates a cell death response in $N$. benthamiana (Carter et al. 2019). It is, thus, likely that other crop plants that recognize AvrPphB protease activity also contain an AvrPphB-specific resistance protein that guards PBS1 orthologous proteins.

In the present study, we sought to generate PBS1-based decoys in soybean that would confer recognition of the NIa protease from soybean mosaic virus (SMV) (genus Potyvirus). 
SMV is the most widespread virus that infects soybean and is responsible for significant economic losses worldwide (Hajimorad et al. 2018; Whitham et al. 2016). In addition, the prevalence and severity of losses to SMV in the United States have increased over the last two decades, which has been primarily attributed to the introduction of the soybean-colonizing aphid (Aphis glycines), a vector for SMV (Clark and Perry 2002; Hartman et al. 2001; Hill et al. 2001). SMV is a singlestranded, positive-sense filamentous RNA virus (Hajimorad et al. 2018; Whitham et al. 2016). Upon SMV infection, the viral RNA is translated as a precursor polyprotein that is proteolytically processed by three SMV-encoded proteases at internal cleavage sites to produce mature, multifunctional viral proteins, including P1 (protein 1), HC-Pro (helper component protease), P3 (protein 3), 6K1 (six kiloDalton 1), CI (cylindrical inclusion), 6K2 (six kiloDalton 2), NIa (nuclear inclusion a), $\mathrm{NIb}$ (nuclear inclusion b), and CP (coat protein) (Hajimorad et al. 2018). Significantly, the NIa protease is the only SMVencoded protease that acts in trans (Adams et al. 2005). Further, the minimal amino acid sequence required for recognition by the SMV NIa protease has been previously characterized and is well-conserved among SMV isolates (Adams et al. 2005; Ghabrial et al. 1990; Jayaram et al. 1992). Potyvirus proteases are essential for processing the viral polyprotein into functional viral proteins (Adams et al. 2005). We, therefore, hypothesize that a resistance protein activated by the enzymatic activity of the NIa protease would be a durable disease resistance trait, as it would be unlikely SMV would simultaneously change specificity of the NIa protease and multiple protease cleavage sites embedded within the polyprotein.

The observation that soybean responds to AvrPphB with a HR (Russell et al. 2015) suggests that artificial soybean PBS1based decoys can be engineered to detect the NIa protease from SMV. It was unclear, however, whether the endogenous soybean resistance protein that detects AvrPphB protease activity functions analogously to Arabidopsis RPS5.

Here, we show that soybean contains three plasma membranelocalized PBS1 orthologous proteins (GmPBS1-1, GmPBS1-2, and GmPBS1-3) that are cleaved by AvrPphB. Significantly, transient expression of GmPBS1 derivatives containing a fivealanine insertion at the AvrPphB cleavage site (GmPBS1 ${ }^{5 \mathrm{Ala}}$ ) induces cell death in the absence of AvrPphB, demonstrating that GmPBS1 proteins have a functional role in the innate immune response, likely by being guarded by an NLR protein functionally analogous to RPS5. Significantly, we demonstrate that replacing the native AvrPphB cleavage site sequence with a SMV NIa protease recognition site in GmPBS1-1 (GmPBS1$1^{\mathrm{SMV}}$ ) results in NIa-mediated cleavage and such cleavage activates cell death in soybean protoplasts. Last, we show that SMV-mediated overexpression of AvrPphB inhibits systemic spread of SMV in soybean, demonstrating that the AvrPphBdependent cell death response resulting from GmPBS1 cleavage is effective against a viral pathogen. Collectively, these data suggest that synthetic PBS1-based decoys can be used to expand effector protease recognition in soybean and generating artificial decoys offers an attractive approach for engineering resistance to other soybean pathogens.

\section{RESULTS}

Soybean contains three $P B S 1$ genes that are co-orthologous to Arabidopsis PBS1 and whose protein products are cleaved by AvrPphB.

Pseudomonas syringae pv. glycinea Race 4 expressing the effector protease AvrPphB elicits a HR in soybean (Glycine max), indicating that soybean contains an AvrPphB-specific disease resistance protein (Russell et al. 2015). To confirm these observations, we delivered AvrPphB or an enzymatically inactive derivative of $\mathrm{AvrPphB}, \mathrm{AvrPphB}(\mathrm{C} 98 \mathrm{~S})$, to primary leaves of soybean (cv. Flambeau) using $P$. syringae pv. tomato D36E, which lacks all known endogenous type III effectors (Carter et al. 2019; Wei et al. 2015). Consistent with the observations of Russell et al. (2015), D36E(AvrPphB) induced an observable cell death response $24 \mathrm{~h}$ postinjection, while minimal cell death was observed with D36E(C98S) or D36E carrying the empty vector (Supplementary Fig. S1). These data indicate that soybean likely contains a disease resistance protein that can detect the protease activity of AvrPphB.

Given that Arabidopsis detects AvrPphB protease activity via sensing cleavage of the protein kinase PBS1, we hypothesized that soybean may employ a similar mechanism. We thus screened for soybean PBS1 homologs that can be cleaved by AvrPphB. Using the Arabidopsis PBS1 amino acid sequence (AtPBS1) as a query, we used BLAST to identify the top twenty soybean PBS1-like (GmPBL) protein sequences (release Williams82.a2.v1; SoyBase website) (Grant et al. 2010) with the most similarity to AtPBS1. Phylogenetic analysis showed that Glyma.08G360600, Glyma.10G298400, and Glyma.20G249600 are more closely related to AtPBS1 than to other Arabidopsis or soybean PBL proteins (Fig. 1A; Supplementary Fig. S2). Fulllength amino acid alignments showed that Glyma.08G360600, Glyma.10G298400, and Glyma.20G249600 are 80, 77, and 77\% identical to AtPBS1, respectively (Supplementary Fig. S3), with alignment across just the kinase domains showing even higher identities $(91,92$, and $92 \%)$. Based on the structure of the phylogenetic tree, all three soybean genes are co-orthologous to AtPBS1. We therefore designated Glyma.08G360600 as GmPBS1-1 (GenBank number MK035866), Glyma.10G298400 as GmPBS1-2 (GenBank number MK035867), and Glyma. 20G249600 as GmPBS1-3 (GenBank number MK035868).

The AvrPphB cleavage site sequence is conserved in all three GmPBS1 proteins, suggesting that these proteins should be cleavable by AvrPphB. To test this, GmPBS1-1, GmPBS1-2, and GmPBS1-3 were transiently coexpressed with AvrPphB in $N$. benthamiana. Immunoblot analysis showed that all three proteins are cleaved by AvrPphB and not by AvrPphB(C98S) (Fig. 1B), indicating that recognition of AvrPphB in soybean could be mediated by cleavage of one or more of these three GmPBS1 proteins.

In Arabidopsis, detection of PBS1 cleavage occurs at the plasma membrane, and AtPBS1 is targeted to the plasma membrane via N-terminal myristoylation and palmitoylation motifs (Qi et al. 2014). These motifs are conserved in all three GmPBS1 proteins, so we assessed whether these proteins are also targeted to the plasma membrane using transient expression of superyellow fluorescent protein (sYFP)-tagged versions in $N$. benthamiana. All three proteins displayed a clear plasma membrane localization pattern, colocalizing with the known plasma membrane protein AtFLS2 (Fig. 1C).

\section{Insertion of five alanine residues in the AvrPphB cleavage site of soybean PBS1 proteins activates cell death in the absence of AvrPphB-mediated cleavage.}

The above data are consistent with AvrPphB being recognized via cleavage of one or more GmPBS1 proteins but do not prove it. In Arabidopsis, AvrPphB targets at least nine Arabidopsis PBS1-like (AtPBL) proteins (DeYoung et al. 2012; Zhang et al. 2010). It is, therefore, a formal possibility that soybean detects AvrPphB protease activity by sensing cleavage of an AvrPphB substrate other than GmPBS1 proteins. To assess whether GmPBS1 cleavage does indeed activate resistance in soybean, we inserted five alanine residues at the AvrPphB cleavage site of GmPBS1-1 (Fig. 2A, GmPBS1-1 ${ }^{5 \mathrm{Ala}}$ ). An 
equivalent insertion in AtPBS1 induces a conformational change that activates RPS5-dependent cell death in Arabidopsis in the absence of AvrPphB expression (DeYoung et al. 2012). We thus hypothesized that a five-alanine insertion into one of the GmPBS1 proteins would activate the AvrPphB-specific resistance $(\mathrm{R})$ protein in soybean and, thus, induce cell death. We selected GmPBS1-1 for this assay because it is the most abundantly expressed of the three GmPBS1 co-orthologs in leaves (Libault et al. 2010). We then transiently transfected soybean (cv. Williams 82) protoplasts with either GmPBS1-1 or the GmPBS1-1 ${ }^{5 \mathrm{Ala}}$ derivative along with a Renilla luciferase reporter (Fig. 2B). This assay is based on our previously published biolistic assay in which we showed that codelivery of the $P$. syringae effector gene $a v r B$ and its matching resistance protein Rpg1- $b$ into soybean leaves activates a programmed cell death response that inhibits luciferase expression (Ashfield et al. 2004). A reduction in luciferase activity thus indicates activation of cell death. As positive controls for cell death, we transiently expressed AvrB or AvrPphB, which activate a HR in Williams 82 (Ashfield et al. 2004). Consistent with our
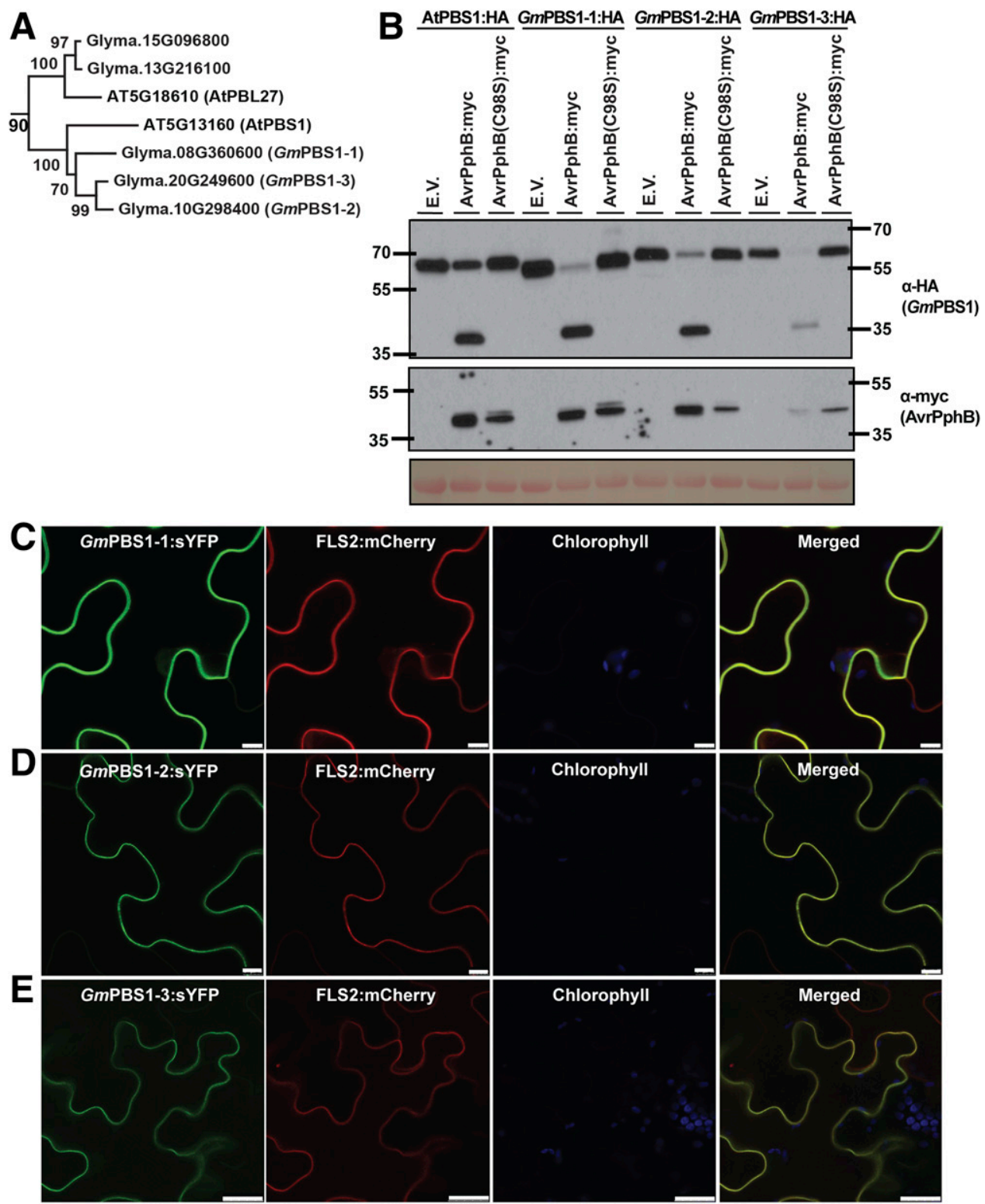

Fig. 1. Soybean contains three PBS1 proteins that localize to the plasma membrane and are cleaved by AvrPphB. A, Glyma.08G360600.3 (GmPBS1-1), Glyma.10G298400.1 (GmPBS1-2), and Glyma.20G249600.2 (GmPBS1-3) are co-orthologous to Arabidopsis PBS1 (AtPBS1). Shown is a phylogenetic tree generated from the amino acid sequences of Arabidopsis PBS1 and the most closely related soybean homologs, using MEGA7, with the neighbor-joining model (Kumar et al. 2016). The bootstrap values are shown at the nodes. This tree is a subset of a larger one that displays soybean proteins closely related to Arabidopsis PBS1 and Arabidopsis PBS1-like (AtPBL) proteins. B, Cleavage of GmPBS1-1, GmPBS1-2, and GmPBS1-3 by AvrPphB. Hemagglutinin (HA)tagged soybean PBS1 homologs or Arabidopsis PBS1 were transiently coexpressed with or without myc-tagged AvrPphB and AvrPphB(C98S) in Nicotiana benthamiana. Total protein was extracted $6 \mathrm{~h}$ post-transgene induction and was immunoblotted with the indicated antibodies. Ponceau S solution staining was included as a control to show equal loading of protein samples. Three independent experiments were performed with similar results. The results of only one experiment are shown. $\mathbf{C}$ to $\mathbf{E}$, The soybean PBS1 proteins localize to the plasma membrane in $N$. benthamiana. superyellow fluorescent protein (sYFP)-tagged Glyma.08G360600.3 (GmPBS1-1) (C), Glyma.10G298400.1 (GmPBS1-2) (D), and Glyma.20G249600.2 (GmPBS1-3) (E), and mCherry-tagged FLS2 were transiently coexpressed in $N$. benthamiana leaves. Live-cell imaging was performed using laser-scanning confocal microscopy $24 \mathrm{~h}$ following transgene induction. FLS2 was included as a reference for plasma membrane localization. Scale bars $=10 \mu \mathrm{m}$, except in C, in which the bar $=25 \mu \mathrm{m}$. Two independent experiments were performed with similar results. The results of only one experiment are shown. 
hypothesis, transient expression of GmPBS1-1 ${ }^{5 \mathrm{Ala}}$ but not wildtype GmPBS1-1 induced cell death similar to that observed with AvrB and AvrPphB, demonstrating that insertion of five alanine residues in the activation loop of GmPBS1-1 activates a cell death response in soybean (Fig. 2B; Supplementary Fig. $\mathrm{S} 4 \mathrm{~A})$. To test whether the cell death response is specific to GmPBS1-1, we transiently transfected soybean protoplasts with either GmPBS1-2 or GmPBS1-2 ${ }^{5 \mathrm{Ala}}$ (Supplementary Fig. S5A) and quantified luciferase activity. Transient expression of GmPBS1-2 $2^{5 \text { Ala }}$ but not GmPBS1-2 also induced cell death equivalent to AvrB and AvrPphB. Collectively, these data suggest that soybean likely senses AvrPphB protease activity via cleavage of a GmPBS1 protein, analogous to the Arabidopsis RPS5-PBS1 recognition system.

\section{SMV NIa protease-mediated cleavage of the GmPBS1-1 ${ }^{\text {SMV }}$ decoy protein activates cell death in soybean protoplasts.}

Our evidence suggesting that soybean contains an AvrPphB recognition system functionally analogous to the Arabidopsis RPS5-PBS1 pathway raises the possibility that soybean PBS1 proteins can be modified to enable cleavage by other pathogen proteases and thus expand the recognition specificity of the AvrPphB-specific $\mathrm{R}$ protein in soybean. We have previously shown that AtPBS1 can be modified to be cleaved by the NIa protease from turnip mosaic virus (TuMV), with transgenic Arabidopsis plants expressing this decoy protein displaying enhanced resistance to TuMV (Kim et al. 2016). To create a suitable soybean PBS1 decoy protein for detection of SMV, we replaced the AvrPphB cleavage site sequence in the activation loop of GmPBS1-1 with a known SMV NIa protease cleavage sequence (ESVLSQS) (Ghabrial et al. 1990) (Fig. 3A). As shown in Figure $3 \mathrm{~B}$, GmPBS1-1 ${ }^{\text {SMV }}$ is cleaved by SMV NIa protease when transiently coexpressed in $N$. benthamiana but not by AvrPphB, while wild-type GmPBS1-1 is cleaved by AvrPphB but not by the SMV NIa protease. We then tested for activation of cell death in soybean cells using the protoplast transformation system described above. Coexpression of the NIa protease with GmPBS1-1 ${ }^{\text {SMV }}$ resulted in a significant reduction in luciferase activity compared with coexpression with wild-type GmPBS1-1, indicating that NIa-mediated cleavage of the GmPBS1-1 ${ }^{\text {SMV }}$ decoy activates cell death in soybean cells (Fig. 3C). To test whether GmPBS1-2 and GmPBS1-3 could also serve as decoys, we replaced the AvrPphB cleavage site sequence with the NIa protease cleavage sequence (Supplementary Fig. 6A and B). Transient coexpression of either GmPBS $1-2^{\text {SMV }}$ or GmPBS1-3 ${ }^{\text {SMV }}$ with the NIa protease in $N$. benthamiana resulted in NIa-mediated cleavage of the decoy proteins. Thus, these data suggest synthetic soybean PBS1 proteins can serve as decoys for the NIa protease from SMV, thereby expanding the recognition specificity of the AvrPphBspecific $\mathrm{R}$ protein in soybean.

\section{Recognition of AvrPphB protease activity in soybean inhibits systemic spread of SMV.}

Our evidence demonstrating that soybean PBS1 proteins can be engineered to confer recognition of the NIa protease from SMV suggests decoy engineering can be extended into soybean. It is unclear, however, whether the cell death response elicited by AvrPphB protease activity is effective against SMV in soybean. Kim et al. (2016) showed that Arabidopsis RPS5 can be activated by sensing cleavage of an engineered PBS1 decoy by the NIa protease from TuMV, thereby broadening its recognition specificity. However, infection of transgenic Arabidopsis expressing the PBS1 decoy protein by TuMV resulted in a lethal systemic necrosis phenotype, demonstrating that RPS5-mediated defense responses confers only partial resistance against TuMV (Kim et al. 2016). To test whether activation of the AvrPphB-dependent cell death response could inhibit systemic spread of SMV in soybean, we used an SMV-mediated transient-expression system to transiently express green fluorescent protein (GFP), AvrPphB, or $\operatorname{AvrPphB}(\mathrm{C} 98 \mathrm{~S})$ in soybean. Using this approach, Wang et al. (2006) showed that AvrB, an effector from P. syringae pv. glycinea, activates defense responses and inhibits systemic spread of SMV into the upper, uninoculated trifoliate leaflets of soybean (cv. Harosoy). We inserted the open reading frames (ORFs) encoding AvrPphB and AvrPphB(C98S) into pSMV-Nv (Fig. $4 A)$. Primary leaves of soybean were mechanically inoculated with DNA of either pSMV-Nv::GFP, pSMV-Nv::AvrPphB, or pSMV-Nv::AvrPphB(C98S). Consistent with the observations of Wang et al. (2006), insertion of the GFP ORF resulted in development of mosaic symptoms and leaf rugosity in the systemic, uninoculated trifoliate leaflets, indicative of successful SMV infection (Fig. 4B). In addition to the observed SMV symptoms, immunoblot analysis showed detectable SMV CP and GFP accumulation in the systemic, uninoculated fourth trifoliate leaflet (Fig. 4C), demonstrating the recombinant virus did not spontaneously delete the $0.7-\mathrm{kb}$ insert and that GFP is stably expressed in planta. In contrast, inoculation of leaves with pSMV-Nv:: $A v r P p h B$ did not result in any systemic SMV symptoms, and no AvrPphB or SMV CP accumulation was detected in the fourth trifoliate leaflet 3 weeks postinoculation (Fig. $4 \mathrm{~B}$ and C). Expression of pSMV-Nv::AvrPphB(C98S), however, resulted in mosaic symptoms and leaf rugosity similar to that observed with pSMV-Nv::GFP as well as detectable AvrPphB protein accumulation in the fourth trifoliate leaflet (Fig. 4B and C). Collectively, these data suggest that activation of the

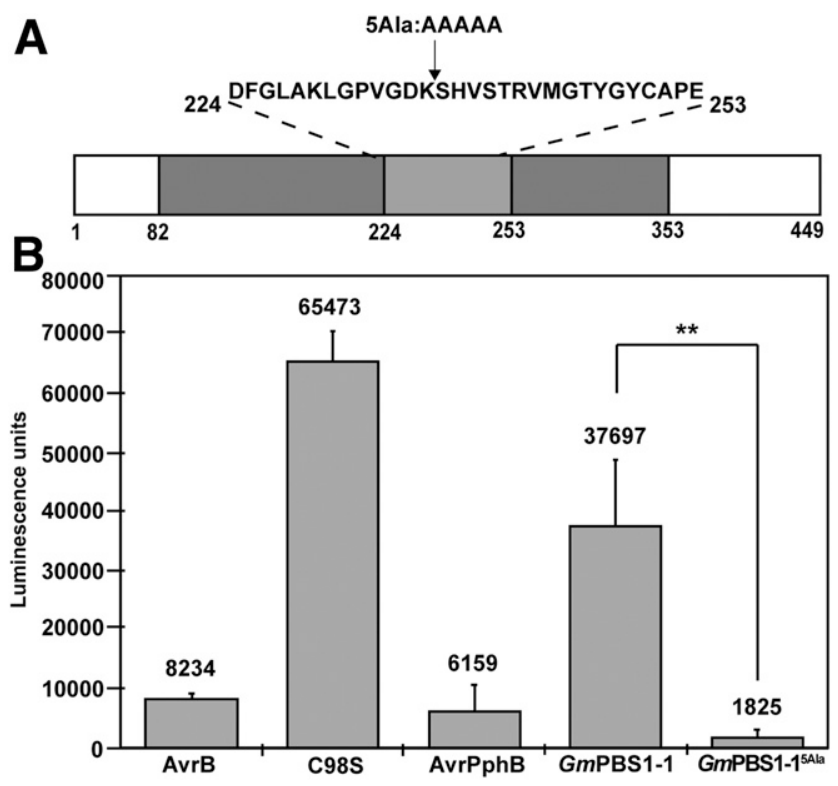

Fig. 2. Transient expression of the GmPBS1-1 $1_{5 \text { Ala }}$ derivative activates cell death in soybean (cv. Williams 82). A, Schematic illustration of the synthetic GmPBS1-1 5 Ala construct. The predicted kinase domain (amino acids 82 to 353 ) and activation segment (amino acids 224 to 253) of GmPBS1-1 are represented by, respectively, dark gray and light gray boxes. The amino acid sequence of the activation segment and the location of the five-alanine insertion are indicated above. B, Transient expression of the GmPBS1-1 15 Ala derivative activates cell death in soybean protoplasts. The indicated constructs were transiently coexpressed along with Renilla luciferase in soybean (Williams 82) protoplasts. Values represent the mean \pm standard deviation for two independent transformations performed in parallel. $T$ tests were performed for the pair-wise comparison. The double asterisk indicates significant difference $(P<0.01)$. Three independent experiments were performed with similar results. Results of one experiment are shown. 
AvrPphB-dependent cell death response effectively inhibits systemic spread of SMV in soybean and, therefore, synthetic decoy engineering may be an effective strategy for engineering resistance to SMV.

\section{DISCUSSION}

We have previously shown that AvrPphB activates a HR in most soybean varieties (Russell et al. 2015), but it was unclear whether this response was mediated by cleavage of a PBL protein and, hence, whether it would be feasible to use a PBS1 decoy strategy to engineer novel recognition specificities in soybean. To address these questions, we first identified soybean PBS1 orthologs and assessed whether the encoded proteins were cleaved by AvrPphB (Fig. 1). These analyses confirmed that GmPBS1 proteins are cleaved by AvrPphB, suggesting that AvrPphB protease activity may be activating NLR-triggered immunity in soybean via a mechanism similar to that employed by Arabidopsis (Ade et al. 2007).

To confirm that GmPBS1 modification activates cell death in soybean, we developed a protoplast transformation assay. Research in soybean is often hampered by the lack of rapid, reproducible transient gene expression methods. Our demonstration of reproducible protoplast assays for cell death following GmPBS1 cleavage thus opens many possibilities for investigating soybean immune signaling. Although routinely used to assess gene function in other plant species, protoplast transformation is often technically challenging, and a robust method for preparation and transformation of soybean protoplasts has only recently been reported (Wu and Hanzawa 2018),
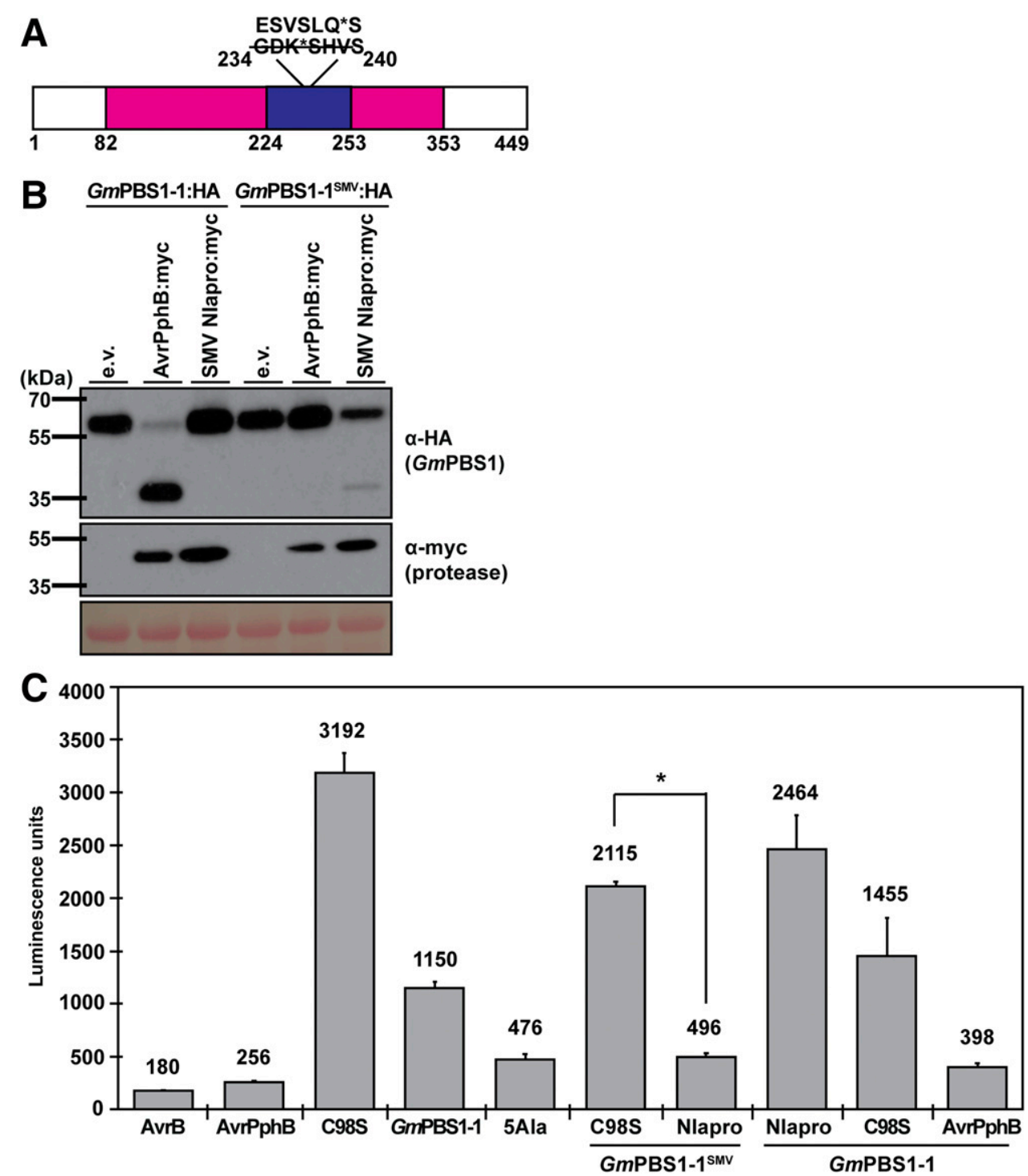

Fig. 3. Soybean mosaic virus (SMV) NIa-mediated cleavage of the GmPBS1-1 ${ }^{\text {SMV }}$ decoy activates cell death in soybean cv. Williams 82 . A, Schematic representation of the synthetic GmPBS1-1 ${ }^{\text {SMV }}$ decoy. The endogenous AvrPphB cleavage site in GmPBS1-1 (GDKSHVS) was substituted with the cleavage site sequence recognized by the SMV NIa protease (ESVSLQS). The asterisks indicate the location of cleavage by the respective proteases within the recognition sites. B, Cleavage of the GmPBS1-1 ${ }^{\text {SMV }}$ synthetic decoy protein by the SMV NIa protease. Hemagglutinin (HA)-tagged GmPBS1-1 ${ }^{\text {SMV }}$ or GmPBS1-1 were transiently coexpressed with either empty vector (e.v.), AvrPphB:myc, or SMV NIapro:myc in Nicotiana benthamiana. Total protein was extracted $9 \mathrm{~h}$ post-transgene induction and was immunoblotted with the indicated antibodies. Ponceau $\mathrm{S}$ solution staining was included as a control to show equal loading of protein samples. Three independent experiments were performed with similar results. The results of only one experiment are shown. C, Cleavage of the GmPBS1-1 ${ }^{\text {SMV }}$ decoy by the NIa protease activates cell death in soybean protoplasts. The indicated constructs were transiently coexpressed along with Renilla luciferase in soybean (Williams 82) protoplasts. Values represent the mean \pm standard deviation for two independent transformations performed in parallel. $T$ tests were performed for the pair-wise comparison. The asterisk indicates significant difference $(P<0.05)$. Two independent experiments were performed with similar results. Results of one experiment are shown. 
who demonstrated expression of GFP and the nuclear localization of the E1 protein (Glyma.06G207800) fused to GFP in soybean protoplasts isolated from the Williams 82 cultivar. Prior to this work, there have been few publications regarding the preparation or use of protoplasts from soybean (Wu and Hanzawa 2018). These include recent papers by Sun et al. (2015) and Kim et al. (2017) who reported gene editing in protoplasts of the Williams 82 soybean cultivar following delivery of DNA constructs expressing Cas9 and guide RNA transgenes and Cpf1-CRISPR RNA ribonucleoprotein complexes, respectively. However, their methods were not described in detail and referred to methods for preparing protoplasts from Arabidopsis leaves or cabbage cotyledons.
These recent studies illustrate the value of using protoplasts to rapidly demonstrate the application of new biotechnology tools in soybean. In Arabidopsis, the use of protoplasts has provided important insight into pattern-recognition receptor-triggered and NLR-triggered signaling mechanisms (He et al. 2007). Here, we demonstrated that soybean protoplasts are useful for rapidly interrogating the functions of proteins in effectortriggered immune signaling.

Once we confirmed that we could express luciferase in soybean protoplasts, we tested whether GmPBS1-1 or GmPBS1-2 containing a five-alanine insertion at the AvrPphB cleavage site activated cell death as assessed by a reduction in luciferase expression. These assays showed that both proteins can activate cell
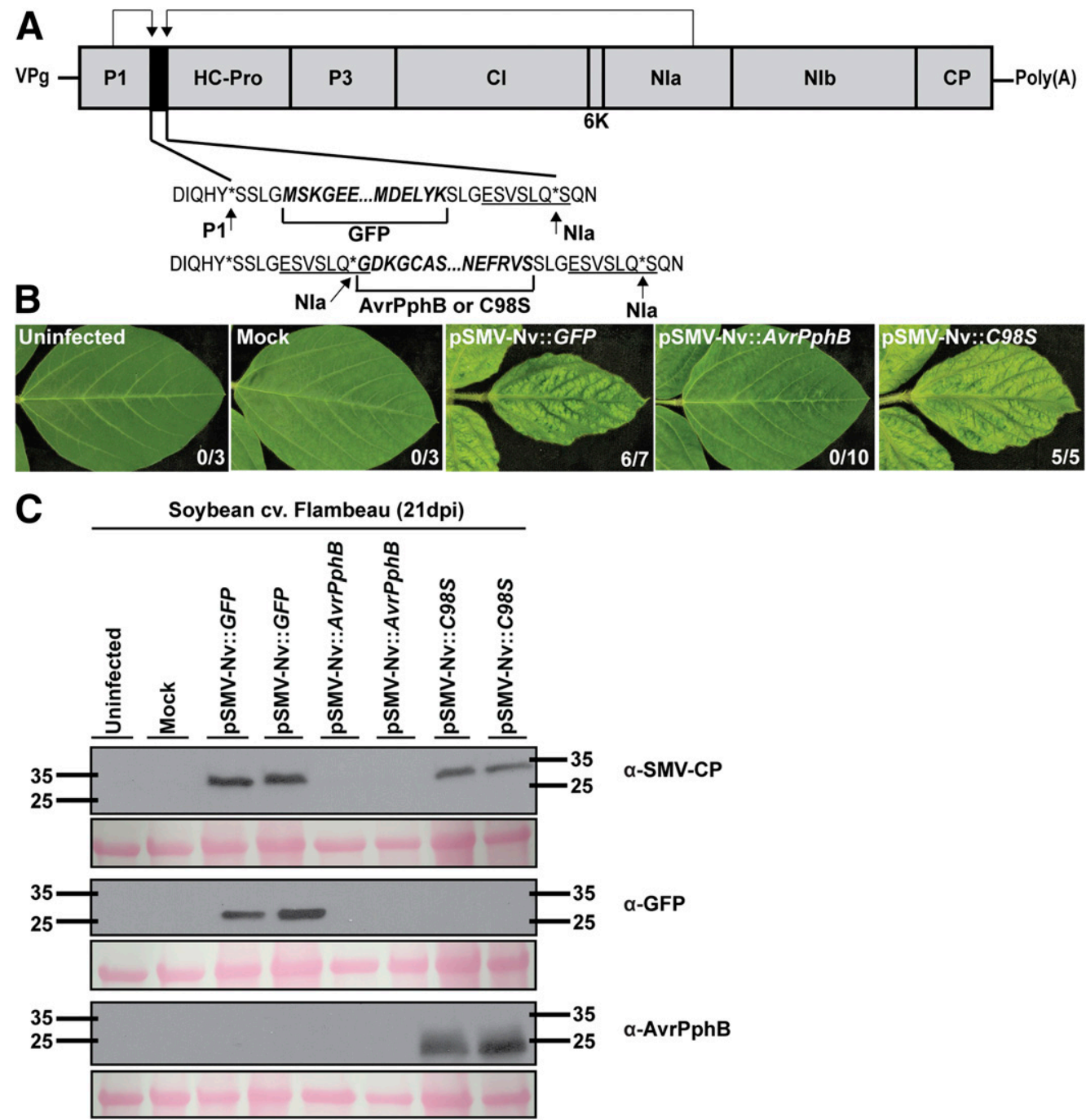

Fig. 4. Recognition of AvrPphB protease activity in soybean blocks soybean mosaic virus (SMV) symptom development and viral protein accumulation in systemic, uninoculated trifoliate leaflets. A, Schematic representation of the SMV-based transient expression system used in this study (adapted from Wang et al. [2006]). The gray boxes represent SMV-N cistrons. The shaded black box indicates the location of transgene insertion. Arrows indicate the positions of the P1 and NIa protease cleavage sites within the SMV-Nv polyprotein. Cleavage by the P1 and the NIa proteases at the respective cleavage sites (indicated by the arrows) releases green fluorescent protein (GFP), AvrPphB, or AvrPphB(C98S) from the SMV polyprotein. The SMV NIa protease recognition site is underlined. B, Recognition of AvrPphB protease activity in soybean (cv. Flambeau) inhibits SMV movement into uninoculated trifoliate leaflets. Fourteen-dayold soybean (Flambeau) primary leaves were rub-inoculated with either mock (buffer) or 35S-driven infectious complementary (c)DNAs of strain SMV-Nv expressing GFP (pSMV-Nv::GFP), AvrPphB (pSMV-Nv::AvrPphB), or AvrPphB(C98S) (pSMV-Nv::C98S). Three weeks postinoculation, the fourth trifoliate leaflet was photographed under white light. The numbers on the right bottom of the photographs indicate the sum of trifoliate leaflets displaying viral symptoms consistent with SMV infection divided by total number of plants rub-inoculated with infectious cDNAs. Two independent experiments were performed with similar results. The results of only one experiment are shown. C, Western blot analysis shows SMV coat protein (SMV-CP) accumulation in the systemic trifoliate leaflets of soybean (Flambeau) inoculated with pSMV-Nv::GFP and pSMV-Nv::C98S and not pSMV-Nv::AvrPphB. Three weeks postinoculation, the fourth trifoliate leaflet was flash-frozen in liquid nitrogen, total protein was extracted, and protein concentration was estimated by Bradford assay (Bradford 1976). Ten micrograms of total protein was separated on 4 to $20 \%$ gradient Precise protein gels and was immunoblotted with the indicated antibodies. Lanes with duplicate labels indicate independent biological replicates. Ponceau S solution staining was included as a control to show equal loading of protein samples. Two independent experiments were performed with similar results. The results of one experiment are shown. 
death in the absence of AvrPphB (Fig. 2). An equivalent insertion in the Arabidopsis PBS1 protein activates the Arabidopsis RPS5 NLR resistance protein, leading to activation of a HR (DeYoung et al. 2012; Kim et al. 2016); thus, these data strongly suggest that soybean contains a putative NLR protein, functionally analogous to RPS5, that is activated by a conformational change in soybean PBS1 proteins. Collectively, these data indicate that it should be possible to engineer novel disease resistance specificities in soybean using a PBS1-based decoy strategy, as was done in Arabidopsis (Kim et al. 2016).

To enable recognition of the NIa protease from SMV, we replaced the AvrPphB cleavage site within GmPBS1-1 with a seven-amino acid sequence cleaved by the NIa protease (Fig. 3). Coexpression of this decoy derivative of GmPBS1-1 with the NIa protease triggered cell death in soybean protoplasts, indicating that the PBS1 decoy approach will work in soybean using endogenous $P B S 1$ genes. Significantly, GmPBS1-2 2 SMV and GmPBS1-3 ${ }^{\text {SMV }}$ were also cleaved by the NIa protease and thus can likely serve as suitable decoys for the SMV NIa protease. These data strongly suggest that multiple, synthetic soybean PBS1-based decoys can be deployed in parallel to enable recognition of several soybean pathogens at once. We are now in the process of generating transgenic soybean lines expressing the GmPBS $1-1^{\text {SMV }}$ construct.

The evidence presented herein suggests decoy engineering may be an effective strategy to confer resistance against SMV. In support of this expectation, we found that expression of AvrPphB protein from the SMV genome renders SMV avirulent in soybean, whereas a protease-inactive AvrPphB mutant does not (Fig. 4). These data thus indicate that the defense responses elicited from AvrPphB-mediated cleavage of the soybean PBS1 proteins is effective against SMV in soybean. Our data are consistent with the observations of Wang et al. (2006), who showed that expression of the P. syringae AvrB protein from the SMV genome also inhibits systemic SMV infection. Additionally, expression of the P. syringae AvrPto protein from a potato virus X (PVX)-based vector elicits defense responses that prevent systemic spread of PVX in tomato (Tobias et al. 1999). These data establish that plant disease resistance proteins that normally confer resistance to $P$. syringae will also confer resistance to viral pathogens when activated, likely due to rapid hypersensitive cell death responses. Such disease resistance proteins are therefore ideal targets for engineering broad-spectrum disease resistance to biotrophic pathogens.

PBS1-based decoy engineering may be feasible in diverse crop species beyond soybean. PBS1 is well-conserved among flowering plants, with orthologs present in monocot and dicot crop plant species (Caldwell and Michelmore 2009). Furthermore, AvrPphB has now been shown to cleave PBS1 orthologous proteins in soybean, barley, and wheat and to activate immune responses in all three species (Carter et al. 2019; Sun et al. 2017). In barley, this immune response is mediated by an NLR protein designated PBR1 (Carter et al. 2019). Interestingly, PBR1 appears to have evolved independent from RPS5, thus, the ability to recognize PBS1 cleavage has evolved at least twice in flowering plants, suggesting that selection to guard AvrPphB substrates occurs across species and it should be possible to introduce novel recognition specificities in most plant species that respond to AvrPphB, using synthetic PBS1based decoys.

\section{MATERIALS AND METHODS}

Plant material and growth conditions.

$N$. benthamiana seeds were sown in plastic pots containing Pro-Mix B Biofungicide potting mix supplemented with
Osmocote slow-release fertilizer (14-14-14) and were grown under a 12 -h photoperiod at $22^{\circ} \mathrm{C}$ in growth rooms, with average light intensities at plant height of $150 \mu$ Einsteins $\mathrm{m}^{-2} \mathrm{~s}^{-1}$.

Seed for soybean [Glycine max (L.) Merr.] cultivars were ordered from the United States Department of Agriculture Soybean Germplasm Collection via the National Plant Germplasm System Web portal. Soybean plants were sown in clay pots containing Pro-Mix B Biofungicide potting mix supplemented with Osmocote slow-release fertilizer (14-14-14) andwere grown in a growth chamber under a 16-h light and 8-h dark photoperiod at $23^{\circ} \mathrm{C}$ with average light intensities at plant height of $300 \mu$ Einsteins $\mathrm{m}^{-2} \mathrm{~s}^{-1}$.

\section{$P$ syringae $\mathrm{DC3000}(\mathrm{D} 36 \mathrm{E})$ in planta assays.}

Previously generated plasmids pVSP61-AvrPphB and pVSP61-AvrPphB(C98S) (a protease-inactive derivative of AvrPphB) (Shao et al. 2003; Simonich and Innes 1995) were transformed into D36E, a derivative of Pseudomonas syringae pv. tomato DC3000 with all type III effector genes removed (Wei et al. 2015). Bacteria were grown on King's medium B (KB) supplemented with rifampicin $(100 \mu \mathrm{g} / \mathrm{ml})$ and kanamycin $(50 \mu \mathrm{g} / \mathrm{ml})$, for 2 days at $30^{\circ} \mathrm{C}$. Bacterial lawns of each strain were grown from single colonies selected on $\mathrm{KB}$ medium. $P$. syringae DC3000(D36E) strains were resuspended in $10 \mathrm{mM} \mathrm{MgCl} 2$ to an optical density at $600 \mathrm{~nm}\left(\mathrm{OD}_{600}\right)$ of 0.2 for each strain. Bacterial suspensions were infiltrated into the abaxial surface of 14-day-old primary leaves of soybean (Flambeau) seedlings using a 1-ml disposable needleless syringe. Responses were photographed 2 days after infiltration, using a high-intensity long-wave $(365 \mathrm{~nm})$ ultraviolet lamp (Black-Ray B-100AP, UVP).

\section{Phylogenetic analyses.}

Soybean PBS1 (GmPBS1) and GmPBL homologs were identified by using the SoyBase genome browser (release Williams82.a2.v1) (Grant et al. 2010) to search the soybean genome with Arabidopsis PBS1 and Arabidopsis PBL proteins (PBL1 through PBL27) as queries. Twenty-two soybean protein sequences were identified as homologous to Arabidopsis PBS1. Amino-acid alignments were made using MUSCLE with default parameters. Phylogenetic trees were generated for the collected sequences using the program MEGA7 under a neighbor-joining model, and clades were assessed using 1,000 bootstrap repeats (Kumar et al. 2016).

\section{Plasmid construction and site-directed mutagenesis.}

The AvrPphB:myc, AvrPphB(C98S):myc, and AtPBS1:HA (hemagglutinin) constructs have been described previously (Ade et al. 2007; DeYoung et al. 2012; Shao et al. 2003). Glyma.08G360600 (GmPBS1-1), Glyma.10G298400 (GmPBS1-2), and Glyma.20G249600 (GmPBS1-3) were PCR-amplified with $a t t B$-containing primers from soybean Flambeau complementary (c)DNA and were then sequenced (Supplementary Table S1 provides a list of primers used). These cDNA sequences matched splice variants Glyma.08G360600.3, Glyma.10G298400.1, and Glyma. 20G249600.2, respectively, and were also the most similar to Arabidopsis PBSI among the splice variants for each gene. The SMV NIa protease was PCR-amplified from pSMV-34 (Ghabrial et al. 1990) using primers designed to introduce $a t t B$ sites. The resulting fragments were gel-purified using the QIAquick gel extraction kit (Qiagen) and were recombined into the Gateway entry vector $\mathrm{pBSDONR}(\mathrm{P} 1-\mathrm{P} 4)$ using the BP Clonase II kit (Invitrogen) (Qi et al. 2012). The resulting constructs were sequence-verified to check for proper sequence and reading frame and were subsequently designated pBSDONR(P1-P4): GmPBS1-1, pBSDONR(P1-P4):GmPBS1-2, pBSDONR(P1-P4): GmPBS1-3, and pBSDONR(P1-P4):NIapro. 
To generate the GmPBS1-1 ${ }^{\text {SMV }}$, GmPBS1-2 ${ }^{\text {SMV }}$, GmPBS1$3^{\mathrm{SMV}}, \mathrm{GmPBS} 1-1^{5 \mathrm{Ala}}$, and GmPBS $1-2^{5 \mathrm{Ala}}$ derivatives, we used an established site-directed mutagenesis PCR protocol using pBSDONR(P1-P4):GmPBS1-1, pBSDONR(P1-P4):GmPBS12 , and pBSDONR(P1-P4):GmPBS1-3 as templates (Qi and Scholthof 2008). The resulting constructs were sequenceverified and were designated $\mathrm{pBSDONR}(\mathrm{P} 1-\mathrm{P} 4): G m P B S 1-$ $1^{S M V}$, pBSDONR(P1-P4):GmPBS1-2 $2^{S M V}$, pBSDONR(P1-P4): GmPBS1-3 ${ }^{S M V}$, pBSDONR(P1-P4):GmPBS1-1 $1^{5 A l a}$, and pBSDONR(P1-P4):GmPBS1-2 ${ }^{\text {5Ala }}$.

To generate protein fusions with $\mathrm{C}$-terminal epitope tags or fluorescent proteins, the pBSDONR(P1-P4):GmPBS1-1, pBSDONR(P1-P4):GmPBS1-2, pBSDONR(P1-P4):GmPBS13, pBSDONR(P1-P4):GmPBS1-1 ${ }^{S M V}$, pBSDONR(P1-P4): GmPBS1-2 $2^{S M V}$, and pBSDONR(P1-P4):GmPBS1-3 ${ }^{S M V}$ constructs were mixed with either the pBSDONR(P4r-P2):3xHA or pBSDONR(P4r-P2):SYFP constructs and the Gatewaycompatible expression vector pBAV154 (pBAV154 is a derivative of the destination vector pTA7001 and contains a dexamethasone (DEX)-inducible promoter; [Vinatzer et al. 2006]) in a 2:2:1 molar ratio. The pBSDONR(P1-P4):NIapro construct was mixed with pBSDONR(P4r-P2):5xmyc and pBAV154 in a 2:2:1 molar ratio. Plasmids were recombined by the addition of LR Clonase II (Invitrogen) and were incubated overnight at $25^{\circ} \mathrm{C}$ following manufacturer instructions. pBAV154-based DEX-inducible constructs were sequenceverified and were subsequently used for transient expression assays in N. benthamiana (Aoyama and Chua 1997). The pBSDONR(P4r-P2):3xHA, pBSDONR(P4r-P2):5xmyc, and pBSDONR(P4r-P2):sYFP constructs have been described previously (Qi et al. 2012).

The pKEx4tr:e.v., pKEx4tr:LUC, and pKEx4tr:AvrB constructs have been described previously (Chern et al. 1996; Leister et al. 1996; Tao et al. 2000). To generate the pKEx4tr: $A v r P p h B$ and pKEx4tr:AvrPphB(C98S) constructs, $A v r P p h B$ and $A v r P p h B(C 98 S)$ were PCR-amplified, using primers designed to introduce BamHI and NotI restriction sites at each end, and the resulting PCR products were cloned into the BamHI-NotI site of pKEx4tr. To generate the pKEx4tr: GmPBS1-1, pKEx4tr:GmPBS1-1 ${ }^{5 A l a}$, pKEx4tr:GmPBS1-1 ${ }^{S M V}$, pKEx4tr:GmPBS1-2, pKEx4tr:GmPBS1-2 $2^{5 A l a}$, and pKEx4tr: NIapro constructs, GmPBS1-1, GmPBS1-1 ${ }^{5 A l a}$, GmPBS1-1 ${ }^{S M V}$, GmPBS1-2, GmPBS1-2 ${ }^{5 A l a}$, and the NIapro were PCRamplified, using primers designed to introduce XhoI and SacI restriction sites, and were cloned into the XhoI-SacI site of pKEx4tr. The resulting constructs were sequence-verified to check for proper sequence and reading frame.

The pSMV-Nv::e.v. and pSMV-Nv::GFP constructs have been described previously (Wang et al. 2006). To construct the pSMV-Nv::AvrPphB and pSMV-Nv::AvrPphB(C98S) clones, $A v r P p h B$ and $A v r P p h B(C 98 S)$ were PCR-amplified, using primers designed to introduce an NIa protease recognition site followed by an AvrII restriction site (Wang et al. 2006). The resulting fragments were gel-purified using the QIAquick gel extraction kit (Qiagen) and were subsequently introduced into the AvrII restriction site in pSMV-Nv (Fig. 3A). The resulting constructs were sequence-verified to check for proper sequence and reading frame.

\section{Agrobacterium-mediated transient expression assays in $N$. benthamiana.}

Transient expression assays were performed as previously described (DeYoung et al. 2012; Kim et al. 2016). Briefly, the DEX-inducible constructs were mobilized into A. tumefaciens GV3101(pMP90) and were streaked onto Luria-Bertani (LB) agar supplemented with gentamicin sulfate $(30 \mu \mathrm{g} / \mathrm{ml})$ and kanamycin $(50 \mu \mathrm{g} / \mathrm{ml})$. Single colonies were inoculated into
$5 \mathrm{ml}$ of liquid LB containing gentamicin sulfate $(30 \mu \mathrm{g} / \mathrm{ml})$ and kanamycin $(50 \mu \mathrm{g} / \mathrm{ml})$ and were shaken overnight at $30^{\circ} \mathrm{C}$ at $250 \mathrm{rpm}$ on a New Brunswick rotary shaker. After overnight culture, the bacterial cells were pelleted by centrifuging at $3,000 \times g$ for $3 \mathrm{~min}$ and were resuspended in $10 \mathrm{mM} \mathrm{MgCl}_{2}$ supplemented with $100 \mu \mathrm{M}$ acteosyringone (Sigma-Aldrich). The bacterial suspensions were adjusted to an $\mathrm{OD}_{600}$ of 0.3 prior to agroinfiltration and were incubated for $3 \mathrm{~h}$ at room temperature. For coexpression of multiple constructs, the bacterial suspensions were mixed in equal ratios. Bacterial suspensions were infiltrated by needleless syringe into expanding leaves of 3-week-old $N$. benthamiana. Protein expression was induced $40 \mathrm{~h}$ following agroinfiltration by spraying the leaves with $50 \mu \mathrm{M}$ DEX supplemented with $0.02 \%$ Tween 20 . Samples were harvested for protein extraction at the indicated timepoints after DEX application, were flash-frozen in liquid nitrogen, and were stored at $-80^{\circ} \mathrm{C}$.

\section{Immunoblot analyses of $\boldsymbol{N}$. benthamiana leaves.}

For total protein extraction, frozen $N$. benthamiana leaf tissue $(0.5 \mathrm{~g})$ was ground in two volumes of protein extraction buffer $(150 \mathrm{mM} \mathrm{NaCl}, 50 \mathrm{mM}$ Tris [pH 7.5], 0.1\% Nonidet P-40 [Sigma-Aldrich], $1 \%$ plant protease inhibitor cocktail [Sigma-Aldrich], and 1\% 2,2'-dipyridyl disulfide [ChemImpex]), using a cold ceramic mortar and pestle. Homogenates were centrifuged at $10,000 \times g$ for $10 \mathrm{~min}$ at $4^{\circ} \mathrm{C}$ to pellet debris. Eighty microliters of total protein lysate were combined with $20 \mu \mathrm{l}$ of $5 \times$ sodium dodecyl sulfate (SDS) loading buffer (250 mM Tris- $\mathrm{HCl}$ [pH 6.8], 10\% SDS, 30\% (vol/vol) glycerol, $0.05 \%$ bromophenol blue, and $5 \% \beta$-mercaptoethanol), and the mixture was boiled at $95^{\circ} \mathrm{C}$ for $10 \mathrm{~min}$. All samples were resolved on a 4 to $20 \%$ gradient precise protein gels (Thermo Fisher Scientific) and were separated at $180 \mathrm{~V}$ for $1 \mathrm{~h}$ in $1 \times$ Tris/glycine/SDS running buffer. Total proteins were transferred to a nitrocellulose membrane (GE Water and Process Technologies). Ponceau staining was used to confirm equal loading and transfer of protein samples. Membranes were washed with $1 \times$ Tris-buffered saline $(50 \mathrm{mM}$ Tris- $\mathrm{HCl}, 150 \mathrm{mM}$ $\mathrm{NaCl}, \mathrm{pH} 7.5$ ) solution containing $0.1 \%$ Tween 20 (TBST) and were blocked with 5\% Difco skim milk (Becton, Dickinson \& Company) for $1 \mathrm{~h}$ at room temperature. Proteins were detected with 1:5,000 diluted peroxidase-conjugated anti-HA antibody (rat monoclonal, Roche) and a 1:5,000 diluted peroxidaseconjugated antic-Myc antibody (mouse monoclonal, Thermo Fisher Scientific) for $1 \mathrm{~h}$ and were washed three times for $15 \mathrm{~min}$ in TBST solution. Protein bands were imaged using Immuno-Star reagents (Bio-Rad) and X-ray film.

\section{Fluorescence microscopy in $N$. benthamiana.}

Laser-scanning confocal microscopy assays were performed as previously described (Qi et al. 2012). To image protein fusions in live $N$. benthamiana cells, microscopy was performed using an SP5 AOBS inverted confocal microscope (Leica Microsystems) equipped with a $63 \times$ numerical aperture 1.2 water objective. The sYFP fusion proteins were excited using a 514-nm argon laser and fluorescence was detected using a 522to 545-nm band-pass emission filter. mCherry fluorescence (excited with a 561-nm helium-neon laser) was detected using a custom 595- to 620-nm band-pass emission filter.

\section{Soybean protoplast isolation and transient expression assays.}

Soybean protoplast isolation and transient expression assays were performed as described previously (Wu and Hanzawa 2018) with minor modifications. Newly expanded unifoliate leaves from the growth chamber-grown (under a 16-h photoperiod at $22^{\circ} \mathrm{C}$ ) 12 -day-old soybean (Williams 82 ) were cut into 
0.5 - to 1-mm leaf strips and were gently immersed into an enzyme solution (0.4 M mannitol, $20 \mathrm{mM}$ MES [pH 5.7], $20 \mathrm{mM} \mathrm{KCl}, 2 \%$ [wt/vol] cellulase R-10 [Yakult], $0.1 \%$ [wt/vol] pectolyase Y-23 [Kyowa], $10 \mathrm{mM} \mathrm{CaCl}, 0.1 \%$ [wt/vol] bovine serum albumin, $0.5 \mathrm{mM}$ dithiothreitol) and were incubated under vacuum pressure $(25 \mathrm{~mm} \mathrm{Hg})$ for $30 \mathrm{~min}$. Following vacuum infiltration, the leaf strips were incubated in the enzyme solution for $6 \mathrm{~h}$ in the dark at room temperature with gentle agitation ( peed $=30$, tilt $=1$ ) on a threedimensional Rotator Waver (VWR International). After adding $5 \mathrm{ml}$ of W5 solution $\left(154 \mathrm{mM} \mathrm{NaCl}, 125 \mathrm{mM} \mathrm{CaCl}_{2}, 2 \mathrm{mM}\right.$ MES [pH 5.7], $5 \mathrm{mM} \mathrm{KCl})$, the enzyme and protoplast solution was filtered through $75-\mu \mathrm{m}$ nylon mesh into a $50-\mathrm{ml}$ roundbottom tube. The protoplast cells were collected by centrifuging at $100 \times g$ for $3 \mathrm{~min}$, were washed once with W5 solution, and were resuspended with MMG solution (0.4 M mannitol, $4 \mathrm{mM}$ MES [pH 5.7], $15 \mathrm{mM} \mathrm{MgCl}_{2}$ ) to the final concentration at $10^{6} \mathrm{ml}^{-1}$ on ice. Five hundred microliters of protoplast cells $\left(5 \times 10^{5}\right)$ were aliquoted and mixed with $50 \mu \mathrm{g}$ of freshly prepared plasmids and $550 \mu \mathrm{l}$ of PEG solution $(40 \%$ [wt/vol] PEG4000, $200 \mathrm{mM}$ mannitol, $100 \mathrm{mM} \mathrm{CaCl}_{2}$ ) for $15 \mathrm{~min}$ at room temperature. To stop the transfection, the protoplast cells were washed with $2 \mathrm{ml}$ of W5 solution and were resuspended in $500 \mu \mathrm{l}$ of WI solution (0.5 M mannitol, $4 \mathrm{mM}$ MES [pH 5.7], $20 \mathrm{mM} \mathrm{KCl})$. After overnight incubation under low fluorescent light $\left(4 \mu \mathrm{mol} \mathrm{m} \mathrm{m}^{-2} \mathrm{~s}^{-1}\right)$ and room temperature conditions, the transfected protoplast cells were gently centrifuged $(100 \times g$ for $3 \mathrm{~min}$ ) and were resuspended in $50 \mu \mathrm{l}$ of WI solution. Ten microliters of substrate solution (ViviRen) was mixed with the resuspended protoplasts and the luminescence signal from each sample was recorded using a BioTek Synergy HT plate reader. For each DNA construct, two parallel transformations were performed per experiment and the resulting luminescence values were averaged. A mock transformation with no DNA was also performed for each experiment and the luminescence value for the mock sample was subtracted from the values for all other samples in order to subtract background luminescence. All protoplast transformation experiments were performed at least twice.

\section{Introduction of SMV-Nv constructs into soybean.}

The pSMV-Nv::e.v., pSMV-Nv::GFP, pSMV-Nv::AvrPphB, and pSMV-Nv::AvrPphB(C98S) constructs were transformed into Escherichia coli TOP10 and were streaked onto LB medium supplemented with carbenicillin $(100 \mu \mathrm{g} / \mathrm{ml})$ and $20 \mathrm{mM}$ glucose at $30^{\circ} \mathrm{C}$. Single colonies were inoculated into $500 \mathrm{ml}$ of liquid LB supplemented with carbenicillin $(100 \mu \mathrm{g} / \mathrm{ml})$ and $20 \mathrm{mM}$ glucose and were shaken overnight at $30^{\circ} \mathrm{C}$ on a New Brunswick rotary shaker. After overnight culture, plasmid DNAs of pSMV-Nv::e.v., pSMV-Nv::GFP, pSMV-Nv:: $A v r P p h B$, and pSMV-Nv::AvrPphB(C98S) were prepared using the plasmid Maxiprep kit (Qiagen).

Introduction of infectious pSMV-Nv and pSMV-Nv-based derivatives into soybean was performed as previously described (Seo et al. 2009). Briefly, $10 \mu \mathrm{g}$ of each infectious cDNA clone was diluted in $50 \mathrm{mM}$ potassium phosphate $(\mathrm{pH}$ 7.5) to a total volume of $80 \mu \mathrm{l}$ and was rub-inoculated with Carborundum onto the abaxial surface of 14-day-old primary leaves of soybean (Flambeau) seedlings. Following mechanical inoculation, plants were maintained in a growth chamber under a 16-h light and 8-h dark photoperiod at $23^{\circ} \mathrm{C}$. At 3 weeks postinoculation, the fourth trifoliate leaflet was photographed under white light, was flash-frozen in liquid nitrogen, and was stored at $-80^{\circ} \mathrm{C}$.

\section{Immunoblot analysis of soybean leaves.}

Immunoblot analyses were performed as described previously (Seo et al. 2009). For total protein extraction, flash-frozen fourth trifoliate leaflets were ground in three volumes of protein extraction buffer (20 mM Tris- $\mathrm{HCl}$ [pH 7.5], $300 \mathrm{mM} \mathrm{NaCl}$, $5 \mathrm{mM} \mathrm{MgCl}_{2}, 5 \mathrm{mM}$ dithiothreitol, $0.5 \%$ Triton $\mathrm{X}-100,1 \%$ plant protease inhibitor cocktail [Sigma-Aldrich], and 1\% 2,2'dipyridyl disulfide [Chem-Impex]). Homogenates were centrifuged twice at $10,000 \times g$ for $10 \mathrm{~min}$ at $4^{\circ} \mathrm{C}$ to pellet debris. Total protein concentration was estimated by the Bradford assay (Bradford 1976). Total protein lysate (10 $\mu \mathrm{g})$ was combined with $5 \times$ SDS loading buffer and the mixture was boiled at $95^{\circ} \mathrm{C}$ for $10 \mathrm{~min}$. All samples were resolved on a 4 to $20 \%$ gradient Precise protein gels (Thermo Fisher Scientific) and were separated at $185 \mathrm{~V}$ for $1 \mathrm{~h}$ in $1 \times$ Tris/glycine/ SDS running buffer. Total proteins were transferred to a nitrocellulose membrane (GE Water and Process Technologies). Ponceau staining was used to confirm equal loading and transfer of protein samples. Membranes were washed with $1 \times$ TBST and were blocked with 5\% Difco skim milk (Becton, Dickinson \& Company) overnight at $4{ }^{\circ} \mathrm{C}$. Nitrocellulose membranes were incubated with either 1:5,000 monoclonal mouse anti-GFP antibody (Novus Biologicals), 1:5,000 polyclonal rabbit anti-AvrPphB antisera, or $1: 10,000$ polyclonal rabbit anti-SMV-CP antibody (Hunst and Tolin 1982) for $1 \mathrm{~h}$ at room temperature and were washed overnight in TBST solution at $4^{\circ} \mathrm{C}$. Proteins were detected with either 1:5,000 horseradish peroxidase-conjugated goat antimouse antibody (abcam) or 1:5,000 peroxidase-conjugated goat antirabbit antibody (abcam) for $1 \mathrm{~h}$ at room temperature. The nitrocellulose membranes were washed three times for $15 \mathrm{~min}$ in TBST solution and protein bands were imaged using Immuno-Star reagents (Bio-Rad) or Supersignal West Femto maximum sensitivity substrates (Thermo Scientific) and X-ray film.

\section{ACKNOWLEDGMENTS}

The authors thank A. Eggenberger and J. Hill for generously providing the pSMV-Nv and pSMV-Nv::GFP plasmids; S. Ghabriel for supplying the pSMV-34 plasmid; S. Tolin for kindly providing antibody for the SMV coat protein; A. Margets and L. Joseph for technical laboratory assistance; the Indiana University Light Microscopy Imaging Center; M. Carter and B. DeYoung for helpful discussions and critical reading of the manuscript; and the U.S. Department of Agriculture Soybean Germplasm Collection for soybean seed.

\section{LITERATURE CITED}

Adams, M. J., Antoniw, J. F., and Beaudoin, F. 2005. Overview and analysis of the polyprotein cleavage sites in the family Potyviridae. Mol. Plant Pathol. 6:471-487.

Ade, J., DeYoung, B. J., Golstein, C., and Innes, R. W. 2007. Indirect activation of a plant nucleotide binding site-leucine-rich repeat protein by a bacterial protease. Proc. Natl. Acad. Sci. U.S.A. 104:2531-2536.

Aoyama, T., and Chua, N. H. 1997. A glucocorticoid-mediated transcriptional induction system in transgenic plants. Plant J. 11:605-612.

Ashfield, T., Ong, L. E., Nobuta, K., Schneider, C. M., and Innes, R. W. 2004. Convergent evolution of disease resistance gene specificity in two flowering plant families. Plant Cell 16:309-318.

Bradford, M. M. 1976. A rapid and sensitive method for the quantitation of microgram quantities of protein utilizing the principle of protein-dye binding. Anal. Biochem. 72:248-254.

Caldwell, K. S., and Michelmore, R. W. 2009. Arabidopsis thaliana genes encoding defense signaling and recognition proteins exhibit contrasting evolutionary dynamics. Genetics 181:671-684.

Carter, M. E., Helm, M., Chapman, A., Wan, E., Restrepo Sierra, A. M., Innes, R., Bogdanove, A. J., and Wise, R. P. 2019. Convergent evolution of effector protease recognition by Arabidopsis and barley. Mol. PlantMicrobe Interact. 32:550-565.

Chern, M. S., Bobb, A. J., and Bustos, M. M. 1996. The regulator of MAT2 (ROM2) protein binds to early maturation promoters and represses PvALF-activated transcription. Plant Cell 8:305-321.

Clark, A. J., and Perry, K. L. 2002. Transmissibility of field isolates of soybean viruses by Aphis glycines. Plant Dis. 86:1219-1222. 
DeYoung, B. J., Qi, D., Kim, S.-H., Burke, T. P., and Innes, R. W. 2012. Activation of a plant nucleotide binding-leucine rich repeat disease resistance protein by a modified self protein. Cell. Microbiol. 14: 1071-1084.

Ghabrial, S. A., Smith, H. A., Parks, T. D., and Dougherty, W. G. 1990 Molecular genetic analyses of the soybean mosaic virus NIa proteinase. J. Gen. Virol. 71:1921-1927.

Giannakopoulou, A., Steele, J. F. C., Segretin, M. E., Bozkurt, T. O., Zhou, J., Robatzek, S., Banfield, M. J., Pais, M., and Kamoun, S. 2015. Tomato I2 immune receptor can be engineered to confer partial resistance to the oomycete Phytophthora infestans in addition to the fungus fusarium oxysporum. Mol. Plant-Microbe Interact. 28:1316-1329.

Grant, D., Nelson, R. T., Cannon, S. B., and Shoemaker, R. C. 2010. SoyBase, the USDA-ARS soybean genetics and genomics database. Nucleic Acids Res. 38:D843-D846.

Hajimorad, M. R., Domier, L. L., Tolin, S. A., Whitham, S. A., and Saghai Maroof, M. A. 2018. Soybean mosaic virus: A successful potyvirus with a wide distribution but restricted natural host range. Mol. Plant Pathol. 19:1563-1579.

Harris, C. J., Slootweg, E. J., Goverse, A., and Baulcombe, D. C. 2013. Stepwise artificial evolution of a plant disease resistance gene. Proc. Natl. Acad. Sci. U.S.A. 110:21189-21194.

Hartman, G., Domier, L., Wax, L., Helm, C., Onstad, D., Shaw, J., Solter, L., Voegtlin, D., D’Arcy, C., and Gray, M. J. P. H. P. 2001. Occurrence and distribution of Aphis glycines on soybeans in Illinois in 2000 and its potential control. Plant Health Prog. 2:17.

He, P., Shan, L., and Sheen, J. 2007. The use of protoplasts to study innate immune responses. Methods Mol. Biol. 354:1-9.

Hill, J. H., Alleman, R., Hogg, D. B., and Grau, C. R. 2001. First report of transmission of soybean mosaic virus and alfalfa mosaic virus by Aphis glycines in the new world. Plant Dis. 85:561.

Hunst, P. L., and Tolin, S. A. 1982. Isolation and comparison of two strains of soybean mosaic virus. Phytopathology 72:710-713.

Jayaram, C., Hill, J. H., and Miller, W. A. 1992. Complete nucleotide sequences of two soybean mosaic virus strains differentiated by response of soybean containing the Rsv resistance gene. J. Gen. Virol. 73: 2067-2077.

Kim, H., Kim, S.-T., Ryu, J., Kang, B.-C., Kim, J.-S., and Kim, S.-G. 2017. CRISPR/Cpf1-mediated DNA-free plant genome editing. Nat. Commun. 8:14406.

Kim, S. H., Qi, D., Ashfield, T., Helm, M., and Innes, R. W. 2016. Using decoys to expand the recognition specificity of a plant disease resistance protein. Science 351:684-687.

Kumar, S., Stecher, G., and Tamura, K. 2016. MEGA7: Molecular Evolutionary Genetics Analysis version 7.0 for bigger datasets. Mol. Biol. Evol. 33:1870-1874.

Leister, R. T., Ausubel, F. M., and Katagiri, F. 1996. Molecular recognition of pathogen attack occurs inside of plant cells in plant disease resistance specified by the Arabidopsis genes RPS2 and RPM1. Proc. Natl. Acad. Sci. U.S.A. 93:15497-15502.

Libault, M., Farmer, A., Joshi, T., Takahashi, K., Langley, R. J., Franklin, L. D., He, J., Xu, D., May, G., and Stacey, G. 2010. An integrated transcriptome atlas of the crop model Glycine max, and its use in comparative analyses in plants. Plant J. 63:86-99.

Maqbool, A., Saitoh, H., Franceschetti, M., Stevenson, C. E., Uemura, A., Kanzaki, H., Kamoun, S., Terauchi, R., and Banfield, M. J. 2015. Structural basis of pathogen recognition by an integrated HMA domain in a plant NLR immune receptor. eLife 4:4.

Qi, D., DeYoung, B. J., and Innes, R. W. 2012. Structure-function analysis of the coiled-coil and leucine-rich repeat domains of the RPS5 disease resistance protein. Plant Physiol. 158:1819-1832.

Qi, D., Dubiella, U., Kim, S. H., Sloss, D. I., Dowen, R. H., Dixon, J. E., and Innes, R. W. 2014. Recognition of the protein kinase AVRPPHB SUSCEPTIBLE1 by the disease resistance protein RESISTANCE TO PSEUDOMONAS SYRINGAE5 is dependent on s-acylation and an exposed loop in AVRPPHB SUSCEPTIBLE1. Plant Physiol. 164: 340-351.

Qi, D., and Scholthof, K. B. 2008. A one-step PCR-based method for rapid and efficient site-directed fragment deletion, insertion, and substitution mutagenesis. J. Virol. Methods 149:85-90.
Russell, A. R., Ashfield, T., and Innes, R. W. 2015. Pseudomonas syringae effector AvrPphB suppresses AvrB-induced activation of RPM1 but not AvrRpm1-induced activation. Mol. Plant-Microbe Interact. 28: 727-735.

Segretin, M. E., Pais, M., Franceschetti, M., Chaparro-Garcia, A., Bos, J. I. B., Banfield, M. J., and Kamoun, S. 2014. Single amino acid mutations in the potato immune receptor R3a expand response to Phytophthora effectors. Mol. Plant-Microbe Interact. 27:624-637.

Seo, J. K., Lee, H. G., and Kim, K. H. 2009. Systemic gene delivery into soybean by simple rub-inoculation with plasmid DNA of a soybean mosaic virus-based vector. Arch. Virol. 154:87-99.

Shao, F., Golstein, C., Ade, J., Stoutemyer, M., Dixon, J. E., and Innes, R. W. 2003. Cleavage of Arabidopsis PBS1 by a bacterial type III effector. Science 301:1230-1233.

Simonich, M. T., and Innes, R. W. 1995. A disease resistance gene in Arabidopsis with specificity for the avrPph3 gene of Pseudomonas syringae pv. phaseolicola. Mol. Plant-Microbe Interact. 8:637-640.

Stirnweis, D., Milani, S. D., Jordan, T., Keller, B., and Brunner, S. 2014 Substitutions of two amino acids in the nucleotide-binding site domain of a resistance protein enhance the hypersensitive response and enlarge the PM3F resistance spectrum in wheat. Mol. Plant-Microbe Interact. 27 265-276.

Sun, J., Huang, G., Fan, F., Wang, S., Zhang, Y., Han, Y., Zou, Y., and Lu, D. 2017. Comparative study of Arabidopsis PBS1 and a wheat PBS1 homolog helps understand the mechanism of PBS1 functioning in innate immunity. Sci. Rep. 7:5487.

Sun, X., Hu, Z., Chen, R., Jiang, Q., Song, G., Zhang, H., and Xi, Y. 2015. Targeted mutagenesis in soybean using the CRISPR-Cas9 system. Sci. Rep. 5:10342.

Tao, Y., Yuan, F., Leister, R. T., Ausubel, F. M., and Katagiri, F. 2000 Mutational analysis of the Arabidopsis nucleotide binding site-leucinerich repeat resistance gene RPS2. Plant Cell 12:2541-2554.

Tobias, C. M., Oldroyd, G. E. D., Chang, J. H., and Staskawicz, B. J. 1999. Plants expressing the Pto disease resistance gene confer resistance to recombinant PVX containing the avirulence gene AvrPto. Plant J. 17: 41-50.

Vinatzer, B. A., Teitzel, G. M., Lee, M.-W., Jelenska, J., Hotton, S., Fairfax, K., Jenrette, J., and Greenberg, J. T. 2006. The type III effector repertoire of Pseudomonas syringae pv. syringae $\mathrm{B} 728 \mathrm{a}$ and its role in survival and disease on host and non-host plants. Mol. Microbiol. 62:26-44.

Wang, L., Eggenberger, A., Hill, J., and Bogdanove, A. J. 2006 Pseudomonas syringae effector avrB confers soybean cultivar-specific avirulence on Soybean mosaic virus adapted for transgene expression but effector avrPto does not. Mol. Plant-Microbe Interact. 19:304-312.

Wei, H.-L., Chakravarthy, S., Mathieu, J., Helmann, T. C., Stodghill, P., Swingle, B., Martin, G. B., and Collmer, A. 2015. Pseudomonas syringae pv. tomato DC3000 type III secretion effector polymutants reveal an interplay between HopAD1 and AvrPtoB. Cell Host Microbe 17:752-762.

Whitham, S. A., Qi, M., Innes, R. W., Ma, W., Lopes-Caitar, V., and Hewezi, T. 2016. Molecular soybean-pathogen interactions. Annu. Rev Phytopathol. 54:443-468.

Wu, F., and Hanzawa, Y. 2018. A simple method for isolation of soybean protoplasts and application to transient gene expression analyses. J. Vis. Exp. 131:e57258.

Zhang, J., Li, W., Xiang, T., Liu, Z., Laluk, K., Ding, X., Zou, Y., Gao, M., Zhang, X., Chen, S., Mengiste, T., Zhang, Y., and Zhou, J.-M. 2010. Receptor-like cytoplasmic kinases integrate signaling from multiple plant immune receptors and are targeted by a Pseudomonas syringae effector. Cell Host Microbe 7:290-301.

Zhu, M., Shao, F., Innes, R. W., Dixon, J. E., and Xu, Z. 2004. The crystal structure of Pseudomonas avirulence protein AvrPphB: A papain-like fold with a distinct substrate-binding site. Proc. Natl. Acad. Sci. U.S.A. 101:302-307.

\section{AUTHOR-RECOMMENDED INTERNET RESOURCE}

National Plant Germplasm System website: https://www.ars-grin.gov/npgs SoyBase website: https://soybase.org 